\title{
Television advertising and children: lessons from policy development
}

\author{
Martin Caraher ${ }^{1, *}$, Jane Landon ${ }^{2}$ and Kath Dalmeny ${ }^{3}$ \\ 'Department of Health Management and Food Policy, Institute of Health Sciences, City University, Goswell Place, \\ Northampton Square, London EC1 OHB, UK: ${ }^{2}$ National Heart Forum, Tavistock House South, Tavistock Square, \\ London WC1H 9LG, UK: ${ }^{3}$ The Food Commission (UK) Ltd, 94 White Lion Street, London N1 9PF, UK
}

Submitted 12 October 2004: Accepted 4 October 2005

\begin{abstract}
Aim: To conduct a policy review of the regulations related to food advertising on television aimed at children.

Design: The study consisted of documentary analysis of relevant legislation and policy documents related to children's advertising from both industry and nongovernmental organisations at a global level and in 20 countries. This was supported with semi-structured telephone interviews with individuals from 11 countries.

Results: The initial findings resulted in a listing of regulatory impacts from which we developed a taxonomy of regulatory schemes. There was a tension between the development of legislation to cover this area and the use of voluntary agreements and codes. This tension represents a food industry/civic society split. The food and advertising industries are still engaged in a process of denying the impact of advertising on food choice and children as well as commissioning their own research. Outright bans are unusual, with most countries addressing the situation through voluntary agreements and self-regulation. We found a deep division over the way forward and the role and place of legislation. Policy-makers expressed concerns that national legislation was increasingly less relevant in dealing with broadcast media transmitted from outside national boundaries and therefore not subject to the receiving countries' laws but to the laws of the country from which they were transmitted.

Conclusions: The options for the regulation of advertising targeted at children range from (1) a complete ban on advertising as in the case of Sweden, through (2) partial restrictions on advertising by type of food, target group or limits on the amount of advertisements or times shown, to (3) continuation of self-regulation by the advertising and food industries. There is a global dimension to regulation that needs to be built in, as national frontiers are no barriers to broadcast media and public health nutrition needs to ensure that its concerns are heard and addressed.
\end{abstract}

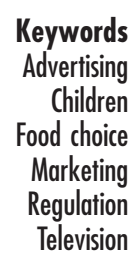

The arena of marketing to children has received much public health attention in recent years ${ }^{1,2}$. In the present paper we report on policy development (both statutory and self-regulatory) with respect to television (TV) advertising targeted to children and the ways in which policies are made and influenced. There is a wideranging debate over the role of the food and advertising industries, how they influence food choice and the extent that this interacts with personal choice ${ }^{3-5}$. Developments in Europe since this research was conducted have resulted in restrictions on advertising with, for example, statutory restrictions on TV advertising to children in Ireland and proposals in France and Norway for a ban on TV advertising ${ }^{6}$. These are reflected in the discussion at the end of the paper. In the UK, the debate has polarised between the findings of a systematic review - the Hastings review - on the impact of advertising on food choice and a report by the regulatory body Ofcom (Office of Communications) on the contribution of children's TV advertising to rising rates of obesity ${ }^{7,8}$.

The key debates and tensions related to advertising policy and children revolve around the following:

- The rights of children and the place of advertising in a child's life.

- The impact of advertising on the attitudes, behaviour and health of children.

- The nutritional quality of foods targeted at children through advertising and other promotional media and methods.

- 'Pester power' and its influence on family food choices.

- The balance between the rights of an industry to promote its products, ideas and communications and 
the role of the state in protecting the health of its citizens and particularly vulnerable groups within the overall population.

The World Health Organization (WHO) has challenged the food industry over the promotion of certain types of fats and processed foods ${ }^{3,9,10}$. A joint WHO/Food and Agriculture Organization $(\mathrm{FAO})^{3}$ report sees advertising as being included in the prevention equation, driven in part by the rise in diet-related non-communicable diseases (DR-NCDs) and specifically by their impact on obesity, and identifies the fast-food industry and the role of advertising as key components in the rise of obesity. It sees the parameters for a dialogue with the food industries $\mathrm{as}^{3}$ :

less saturated fat; more fruits and vegetables; effective food labelling; and incentives for the marketing and production of bealthier products. In working with advertising, media and entertainment partners, there is a need to stress the importance of clear and unambiguous messages to children and youths. Global 'bealth and nutrition literacy' requires a vast increase in attention and resources.

In the UK the Hastings systematic review ${ }^{7}$, for the first time, provided an evidence base for action on limiting the impact of advertising directed to children on health grounds. It is important to note that the Hastings review had as its focus the impact of advertising on food choice, not on obesity or DR-NCDs. The French government has used the findings from this review to ban advertising to children and to introduce legal measures to require food advertisers to display a health warning on advertisements for high-sugar and high-salt foods. If advertisers do not co-operate with this measure, they will be required to pay a $1.5 \%$ tax to finance health promotion ${ }^{11}$. In addition, the recent WHO Global Strategy for diet, physical activity and health includes provisions on marketing, advertising, sponsorship and promotion, as set out in Section 46.3, as follows ${ }^{12}$ :

\begin{abstract}
Marketing, advertising, sponsorship and promotion.
Food advertising affects food choices and influences dietary habits. Food and beverage advertisements should not exploit children's inexperience or credulity. Messages that encourage unhealthy dietary practices or physical inactivity should be discouraged, and positive, healthy messages encouraged. Governments should work with consumer groups and the private sector (including advertising) to develop appropriate multisectoral approaches to deal with the marketing of food to children, and to deal with such issues as sponsorship, promotion and advertising.
\end{abstract}

\section{Methodology}

As Hawkes ${ }^{1}$ points out, there are five other marketing approaches and these are in-school marketing, sponsorship, product placement, Internet marketing and sales promotions. We focused on TV advertising as it still accounts for the largest single budgetary expenditure of food promotion ${ }^{2,13}$.

The aim was to identify existing statutory and selfregulatory policies related to children, TV advertising and food. The objectives were to:

- Determine how these had evolved.

- List the key organisations (actors) involved in the formation of policy.

- Develop an analysis of approaches and types of regulation.

- Develop an understanding of policy formation by identifying key actors and actions in the process of policy development.

We did not focus on the impact or effectiveness of these interventions as this was beyond the scope of the current work. It is not an analysis of the science of eating or of the influence of advertising on behaviour and diet ${ }^{1}$ or of the content and type of food advertised ${ }^{14}$, all of which have been done by others. We did search and ask for evidence of impact or effectiveness and any monitoring data available.

The research consisted of three stages. The first was identification of global and national bodies involved in the regulation and development of policy related to children's advertising in 20 countries (see Table 1); this consisted of gathering copies of policy documents and perusal of relevant websites. We emailed individual contacts in each country, who directed us to relevant websites and/or sent us pertinent documentation. From this initial scoping, the second step involved identification of industry, professional and non-governmental bodies involved in the debates/lobbying and further relevant documents and policy statements/legislation for each of the 20 countries. These first two stages were carried out between March and April of 2003. Documentary analysis from stages 1 and 2 consisted of an initial classification of regulation and key bodies involved in regulating advertising policy directed at children, following which a typology of regulatory types was constructed (see columns 2 and 3, Table 1). The third stage involved 11 individual interviews conducted by telephone in June 2003. The interview schedule used in connection was informed by the first two stages of data collection. These interviews were purposive and were designed to add to the documentary analysis. We approached 25 individuals, 16 were from government or non-governmental groups and nine from the food or advertising industry, but only 11 were available to be interviewed within our window of opportunity. The majority of the food or advertising industry people we contacted did not return our calls and, of those who did, none we talked to agreed to be interviewed. The final breakdown of those interviewed was as follows:

- Four from non-governmental organisations (NGOs) actively engaged in the children and advertising debate (all four from Europe). 
- Three from government agencies involved in proposed regulation of advertising (two from European states and one from the USA).

- Two academics engaged in work for national governments (one from Australia).

- One Government Minister from Europe.

- One staff member from a European Commission office.

This research was not funded and all the researchers were employed full-time at the time of the research. For the purposes of this article we have focused on the global policy situation and that in Europe, and have omitted discussion on the findings from Australia, Canada, New Zealand and the USA. This has been done to provide a coherent focus to the paper, not because the findings were substantially different. A full research report is available from the lead author.

\section{Findings}

Findings are set out under the headings of global/world policy, policy at a European level, followed by case study reports and detailed discussion of the situation in three European countries. The first is Sweden, as it is used by both those calling for greater restrictions to show what can work and those arguing against restrictions. The second is Ireland, as it has been engaged in a process of consultation with all groups on restrictions on children's advertising; moreover, it had led the way in public health terms by banning smoking in public places and many public health advocates were advocating a similar public health approach with food. Then the situation in the UK is set out in light of the Hastings review and the regulatory response. We then discuss the role of the food and advertising industries' formation of policy, the ways in which policy is formulated and present a typology of policy.

\section{Policy at a global level}

The international intergovernmental FAO/WHO Codex Alimentarius Commission is the standard-setting body through which nations agree on standards for food ${ }^{15,16}$. It has been suggested that its work in the area of nutrition and labelling could be extended or strengthened to cover dietrelated aspects of health including codes of practice in food advertising. Any such codes would have to be framed so that they are not barriers to trade, otherwise they may be open to appeal under World Trade Organization (WTO) protocols. There are provisions for limited exceptions to be made by WTO in respect of financial, trade and development needs. There are no specific proposals to regulate children's advertising; it is envisaged that the general principles applied to food advertising in terms of its veracity and (health) claims would apply. These principles apply to both regional governing bodies such as the European Union (EU) and to national governments.

For the advertising industry the gold standard is contained in the International Chamber of Commerce
(ICC) International Code of Advertising Practice. Revised regularly, the Code includes an article on Children and Young People with provisions applying to advertisements addressed to children and young people who are minors under the applicable national law. The provisions cover inexperience and credulity, avoidance of harm and social value. The Code does not:

- Prohibit the advertising of any specific product type.

- Prohibit or control advertising aimed at any particular age group (with the definition of a minor differing from country to country).

- Set limits or make recommendations for control of the frequency/volume of advertising or timing of advertisements during children's viewing.

- Food is not mentioned specifically and the details of any provision are agreed or debated at a national level. This is a feature also of the Swedish government policy, based on the general principles of inexperience, credulity, avoidance of harm and social values ${ }^{17}$. The Swedish case is discussed in more detail below.

This code often forms the basis of both statutory and selfregulatory systems of control.

\section{Policy at a European level}

The current situation for selected individual European states can be found in Table 1 . This sets out a range of approaches from a total ban as in Sweden and Norway, through restrictions (The Netherlands and Italy) to regulations on the content of advertising to children (Greece).

The key policy driver at the European level is enshrined in the EU Television Without Frontiers Directive; this legislation, co-ordinated by the Directorate-General (DG) for Education and Culture, could be an avenue to regulate advertising to children ${ }^{18}$. The Television Without Frontiers Directive (consultation ended in 2004) is a key target for both those seeking limitations and pro-advertising campaigners, because it may set out a number of restrictions which advertisements must adhere to under EU law. If combined with the DG for Health and Consumer Protection's (DG SANCO) Consumer Protection initiative, this offers a powerful force for changing the situation within the EU. In 2001, the Consumer Committee of DG SANCO published a consultation paper on 'Commercial Practices Aimed at Children'. This was roundly condemned by industry representatives as being presumptive in seeking bans in the area of advertising and communications aimed at children. The Advertising Association lobbied hard to have the directive discarded.

The key articles in the Television Without Frontiers Directive are Articles 12 and 16, which state:

- Television advertising and teleshopping shall not encourage behaviour prejudicial to bealth and safety (Article 12). 


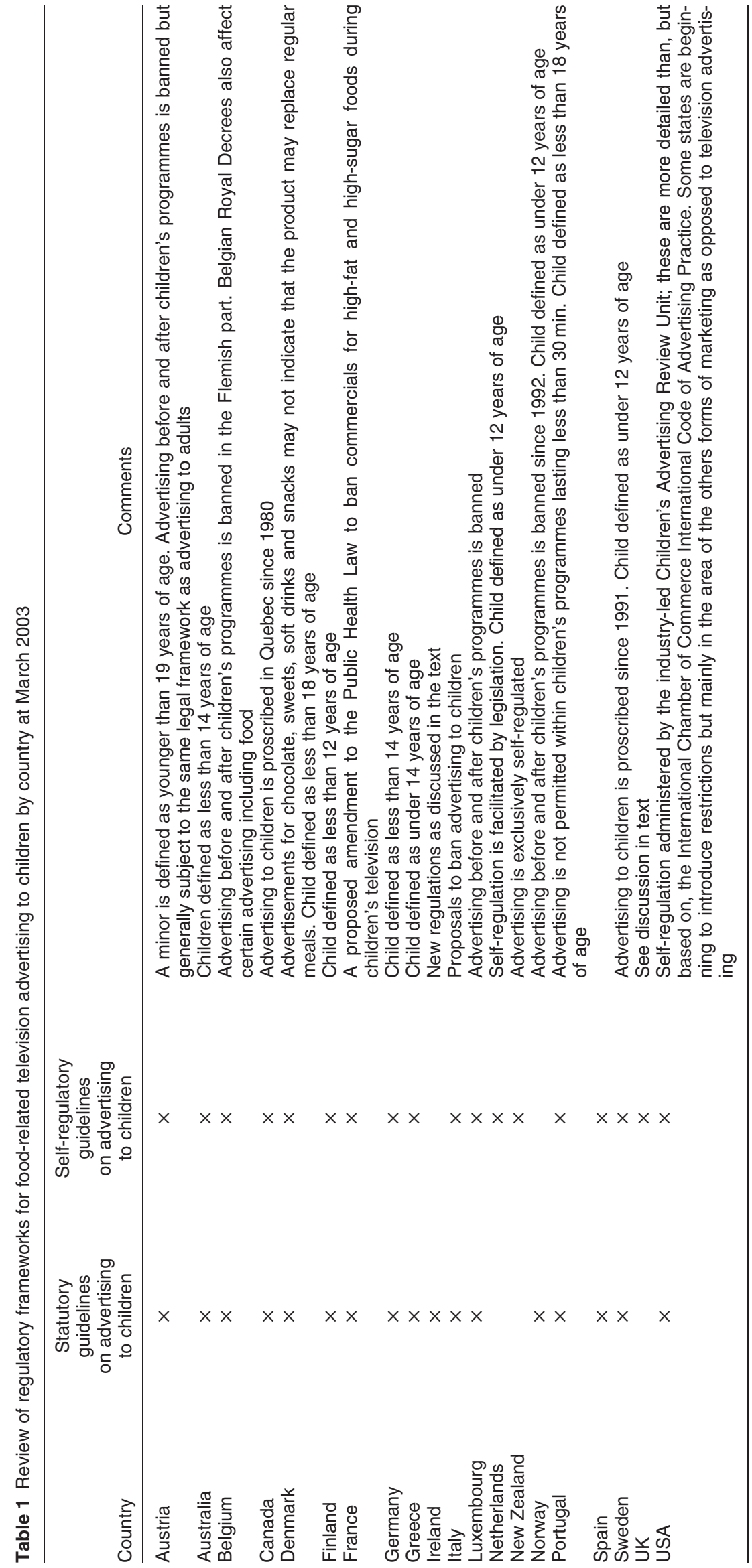


- Television advertising shall not cause moral or physical detriment to minors (Article 16.1).

- It [advertising] shall not directly encourage minors to persuade their parent or others to purchase the goods or services being advertised (Article 16.1(b)).

Currently there appears to be little drive from national governments, or from the DG for Education and Culture or DG SANCO (health) within the European Commission, to seek changes in the regulation of adverting aimed at children or to use and link the Television Without Frontiers Directive with Article 152 of the Amsterdam Treaty, which calls for the EU to examine the possible impact of major policies on public health ${ }^{19}$. Children's advertising could be deemed to come within this remit.

In 2003 the then European Commissioner for Consumer Affairs, David Byrne, announced that the EU will ban 'misleading meaningless claims' and unsubstantiated health claims in order to regulate the food industry and inform consumers. He also proposed a crack down on claims that are accurate but misleading. The Commissioner said that 'any information about foods and their nutritional values in labeling, marketing and advertising which is not clear, accurate and meaningful and cannot be substantiated will not be permitted ${ }^{20}$. The food industry responded by calling the proposal disproportionate and by the Deputy President of the Food and Drink Federation as 'consumer censorship'21,22. Although these regulations will apply to claims made in the context of food promotion, they are not specifically designed to tackle TV advertising or TV advertising directed to children. The implications of the Commissioner's proposed legislation for advertising aimed at children are not clear. Advertising seems to be included, but the focus is on claims concerning the nutritional value of foods not on the targeting of children per se.

\section{Sweden and advertising policy}

The Swedish case is worth presenting at length as it is used both by advocates of a ban to show what can be achieved and by opponents who claim that the ban has failed to halt the rising tide of obesity ${ }^{23-25}$. In Sweden all advertising 'aimed' at children under the age of 12 years is banned, as are advertisements before or after children's programmes. The guiding principle is fair play and protection of children from undue influence ${ }^{26}$.

It also needs to be borne in mind that both these initiatives were introduced not to reduce obesity or to improve health per se but as a matter of human rights. The Swedish case is based not on good or bad food, but on the findings from research that children under 12 years of age cannot clearly distinguish advertising messages from programme content. The Swedish Culture Minister has called for children to be declared a 'commercial-free zone'. The issue was discussed during the Swedish Presidency of the EU in 2001, in preparation for the revision of the EU
Broadcasting Directive in 2002/03. This drive by Sweden for changes in Europe alarmed the advertising lobby, who advised their members that a drive to make the Swedish approach common across Europe would be the beginning of wider bans.

Satellite TV beamed from the UK to Sweden is subject to UK regulations, and brings food advertisements to Swedish children. The EU Television Without Frontiers Directive (based on the 'country of origin' principle) prevents Sweden from stopping this advertising. It is also important to point out that Swedish children are subject to a wide range of marketing activities not covered by the ban, which applies only to broadcast media.

In recent years the Swedish ban of advertising on TV to children has lost some of its strength and this has hinged on appeals on the basis of what constitutes 'aimed' at children. The Swedish Consumer Ombudsman has lost several cases in the Swedish Market Court dealing with marketing on TV to children below 12 years of age. In two of the cases the advertisements were for foods (ice cream and breakfast cereal with high sugar content). The Swedish Market Court argued that if the product in question can be eaten by adults as well, or if the programme the advertisements are shown in connection with can be regarded as targeting the whole family, then the advertisement cannot be considered 'aimed' at children. The practice in the court decisions has shifted from previously focusing on the format of the advertisement (for example, cartoons) to now focusing on the product itself (von Haartman F, personal communication to M.C., Sweden, 2004). Some more recent evidence of this can be seen from the data on advertising budgets for energy-dense products on Swedish TV. For example, in 2003, SEK25 million (€2.6 million) was spent on advertisements for these foods between 07.00 and 08.00 hours, and SEK213 million ( $€ 22.1$ million) between 19.00 and 20.00 hours $^{27,28}$. The Swedish public health movement has recently reiterated its opposition to TV aimed at children and among their proposals are that:

- Sweden should work at the EU level to ensure that TV food advertising targeted at children is banned throughout the EU.

- The prerequisites for restricting food marketing activities targeted at children should be examined, e.g. in respect of existing legislation. Trends in marketing should be continually monitored. A collaborative group for responsible marketing should be created.

- Consumer organisations should be able to apply for funding from the Swedish Consumer Agency for monitoring and publicising developments in the marketing of soft drinks, sweets, crisps, cakes and biscuits and ice cream directed at children, and to initiate a debate on such marketing.

- Material directed at young people about food marketing in relation to health should be produced ${ }^{28}$. 


\section{Irish policy development; unlike smoking!}

At the time of our survey there were proposed changes to the then existing situation of self-regulation, and consultations were being held with interested parties including the food and advertising industries, health lobbies, parents and children by the Broadcasting Commission of Ireland $(\mathrm{BCI})^{29}$. Within Europe, the situation in Ireland was being looked at with interest: in light of the ban on smoking in the workplace, there was hope among public health advocates that Ireland would introduce a ban on food advertising on TV and that during its Presidency of the EU it would push for controls across the EU, but this did not happen. The BCI (see www.bci.ie for more details) has introduced a new code which has moved from a system of self-regulation to one of statutory controls with restrictions and limits to advertising as opposed to an outright ban. It goes further than the UK code but stops short of a ban as in the Swedish case. On 1st January 2005 Ireland introduced the new statutory code which set out that advertisements should:

- Not use celebrities, sports stars or cartoon characters to promote food or drink unless part of public health campaigns.

- Not encourage fast or snack foods as the main part of the diet and clearly place the advertised product in the context of a balanced diet, and include a warning about the role of fast foods in a balanced diet.

- Include an oral health warning logo for certain categories of foods; these will have to carry a message locating them within an overall healthy diet and/or showing a toothbrush symbol on screen.

The then Irish Minster for Health, Michael Martin, who introduced the successful smoking ban in the workplace, was reported as saying that there is insufficient evidence to ban advertising and that 'long terms strategies are needed to tackle Ireland's growing rates of obesity'30. The advertising and food lobbies in Ireland opposed the introduction of these restrictions, claiming that the quality of home-produced children's programmes will suffer from the loss of revenue and that Ireland already receives channels from the UK which will not be subject to the same restrictions; in the same way that commercial TV originating in the UK brings advertisements to children in Sweden. UK channels shown in Ireland will not be subject to Irish regulations based on the 'country of origin' principle. Kerry Foods, a leading producer of dairy products for the UK and Irish markets, said in its submission to the BCI consultation ${ }^{29}$ on a children's advertising code that (p. 13):

As a brand leader in Childrens' [sic] cheese snacking we in Kerry Foods conduct childrens consumer research on a regular basis. The children can be as young as 6. In our experience advertising plays a key communication role in this category for both parties once respected and codes adhered to. Children have a general appreciation for advertising and its usage. They have the ability and necessary language to make their own judgement while understanding the objective of each 'manufacturer'; to deliver awareness, and provide product information. It is a relevant tool for both groups manufacturers and children.

Two interesting aspects of the Irish proposals are that the child is defined as up to 18 years of age (this uses the definition in the UN Convention on the Rights of the Child and is in contrast to the Swedish restrictions, which apply only to those under 12 years of age) and second that the restrictions will be monitored and reviewed over the space of a year from the initial implementation date of 1 st January 2005. Ways to monitor effectively and efficiently are currently being devised with the help of datasets from a market research company; six staff members from BCI have attended training and one will be allocated to work solely on this area. How a public health nutrition voice will be built into the process is not clear.

\section{The $U K$}

Until 2004, the UK situation was based on a voluntary agreement regulated by the Independent Television Commission (ITC) using a Code of Advertising Standards and Practice based on the ICC International Code of Advertising Practice. The bill for the communications industry $^{31}$ established a new regulatory body - the Office of Communications (Ofcom) - to take over regulatory responsibility from the ITC. In the bill there is no specific mention of food and children are mentioned within a framework of choice and media literacy:

Ofcom will promote systems to belp people make informed choices about what they and their children see and hear; and have a duty to promote media literacy, working with DfEE, * the industries and educators.

The Department of Trade and Industry bill ${ }^{31}$ located the use of promotion of material to children within the context of minimising harm. Ofcom commissioned a programme of research to help inform its work including a review of advertising codes; this was partially spurred by the findings of the Hastings review ${ }^{7,8}$. This has concluded that there is insufficient evidence to link advertising to the increases in obesity and that there is no considered reason for a ban on advertising aimed at children. Among their findings were ${ }^{8}$ :

- TV viewing is a sedentary activity that reduces metabolic rates and displaces physical exercise.

- TV viewing is associated with frequent snacking, preprepared meals and/or fast-food consumption.

- TV viewing includes exposure to advertisements for

*The DfEE (Department for Education and Employment) has changed to the DfES, Department for Education and Skills. food products high in fat, salt and sugar. 
From this the conclusions were that children's food preference, consumption and behaviour are influenced by many factors, that adverts on TV form a small part of a larger social issue and that solutions to the prevention of obesity need to be multifaceted. A new Food and Health Action Plan $^{32}$ proposes that a code of conduct be agreed and adopted by the industry by early 2006 , followed by an assessment in early 2007 of the nature and balance of food advertising and promotion on children's food preferences; a decision on whether or not to introduce legislation will then be taken. The process is designed to allow the industry to set its own house in order. The proposals in the Food and Health Action Plan are part of wider public health initiative and are led by the Department of Health, who have no direct power in relation to regulation of advertising.

\section{Type of policy development favoured}

Our analysis and typology of regulatory types shows that the most common form of regulation is that of selfregulation by the industry, with some statutory fall-back controls and/or statutory agency guidance. This was also found by Hawkes on behalf of WHO and in the review of marketing by the European Heart Network ${ }^{1,2}$. In practice, the ways in which self-regulation operate are not clear or consistent from country to country, nor are the links and relationships between statutory regulation and selfregulation transparent. We also found that the monitoring of TV advertising fell between the cracks. There was measurement of input from industry data, so the amount spent by different sectors of the food industry was available. The existing monitoring of advertisements by time, type and target audience was largely carried out by campaigning NGOs, often to stimulate policy action. The self-regulating frameworks are informed by the ICC code of advertising practice mentioned earlier. In many instances the content of statutory regulation and self-regulation are not that different, the differences lie in the areas of enforcement and monitoring. None of the self-regulating bodies we surveyed had any consumer or public health representation on them. Hawkes ${ }^{1}$ also found this in her review of marketing for WHO. Some of those we interviewed from government agencies talked of the benefits of self-regulation as being a 'light touch', requiring fewer resources than statutory regulation and a way of involving the industry. On the negative side the following were mentioned: the lack of suitable sanctions when things go wrong, the lack of consumer involvement, the absence of clear guidance on what constitutes healthy food or diets, and the ability of a powerful industry to shape the research agenda. Those we interviewed saw self-regulation as being a more acceptable approach by politicians.

\section{The food and advertising industries' response}

One of the key advertising lobby groups is the Advertising Association (AA); this is an amalgamation of
$25+$ trade organisations which represent advertisers, advertising agencies, and media and support services. The Food Advertising Unit was formed as a subsidiary of the AA in 1995-1996. This was established to promote the view that the food industry's advertising 'interests and motives were being badly and sometimes deliberately misrepresented'. It provides position papers, conferences, lobbying activities and media releases, particularly relating to TV advertising to children. The European Advertising Standards Alliance based in Brussels focuses on the issues affecting advertising in the EU that can be dealt with through co-operation rather than legislation. A briefing paper on children from the industry's Incorporated Society of British Advertisers (ISBA) ${ }^{33}$ expressed the fear that a move to restrict TV advertising to children under 12 across Europe may be only the first stage in the process of extending restrictions to up to 18 years of age. Those seeking such limitations are branded as 'antiadvertising' with, according to the ISBA, radio and cinema restrictions and sponsorship (marketing) in schools being the next targets.

Analysis of industry documents and policy statement showed that the industry formed its defence and lobbying around the following arguments:

- Self-regulation works better than regulation by the state and is more efficient.

- Advertising revenues contribute to funding quality children's programmes.

- Children are not unduly influenced by advertising and understand more than parents and policy-makers know, and advertising is fact of life in preparing young people to partake in a consumer society (see Young $^{34}$ for articulation of such a standpoint).

- Existing campaigns led by NGOs and academics are unelected and unrepresentative of the community and their concerns.

- Parents and members of the public do not complain; therefore there is no need to regulate or public demand for it.

- The purpose of advertising is to shift brand share or loyalty, not to encourage increases in volume of key food categories.

Media literacy, not regulation, is one of the key solutions proposed by the industry and they support many such programmes. The food but more especially the advertising industry commissioned their own research and denied the impact of advertising aimed at children. There was also some confusion or perhaps obfuscation over the effect of advertising; so studies which showed a food choice effect were often quoted by the industry to show no effect on obesity. Many industry websites reported that the Hastings review showed no link between food intake and obesity, which is true as this was not part of its terms of reference its brief was to examine the impact of advertising on food choice. 
Those from within government departments and the academics and NGO staff whom we interviewed talked of pressure from industry. The consistent lobbying, presentation of industry-sponsored reports and industry-sponsored analysis of existing research were all mentioned as part of the way in which both the food and advertising industries present their case. They talked of this lobbying being 'relentless and at all levels' including direct appeals to ministers and elected members of parliament. The food and advertising industries reportedly spend a lot of resources in this area, while continuing to berate the role of NGOs and branding them as undemocratic and unrepresentative.

\section{Discussion: resistance and reaction}

The foregoing sets the agenda for policy-making, which is a battleground of evidence and counter-evidence, interpretation and spin placed on this evidence. Policymaking with respect to children's advertising is embryonic, more often than not stalemated by the demands of the various interested parties with the situation currently weighted in favour of self-regulation by industry. Battles over policy architecture make formal policy difficult but in general it is driven by NGOs, public sector bodies and academics. The development of formal policy, as in the creation of regulations or legislation, is opposed by the advertising industry especially if it involves more legislation $^{35}$. There is a strong, well-coordinated lobby from the advertising industry for self-regulation and for policy to reflect this approach. Previous attempts at restricting advertising have floundered in the wake of this lobbying. A well-publicised example, from the USA, shows that in 1978 the Head of the US Federal Trade Commission (FTC), Michael Pertshuck, proposed a ban on all TV advertisements directed at children. The proposal was supported by many from the health lobby, while the food and toy industries campaigned against such a ban largely through the agency of the National Association of Broadcasters. Pertshuck was isolated within his own agency, and in 1981 an internal staff report from the FTC argued that a ban on advertisements would be impractical which was accepted by the Reagan administration ${ }^{36}$.

The Hastings review ${ }^{7}$ showed that TV advertising has an impact on children's food choice and that something needs to be done. The European Heart Network report ${ }^{2}$ shows that action needs to be at a Europe level/globally and that national legislation may on its own be insufficient. The ways in which the industry fights back are set out in a Henley Centre forecast, which sees the responses as falling under resistance and reaction (see Fig. 1) ${ }^{37}$. This seesawing of resistance and reaction needs to be tackled by clear policy-making so that there is a clear route through the debate and to ensure that equal opportunity is given to public health nutrition concerns as to those of industry. The power of the food and advertising industries

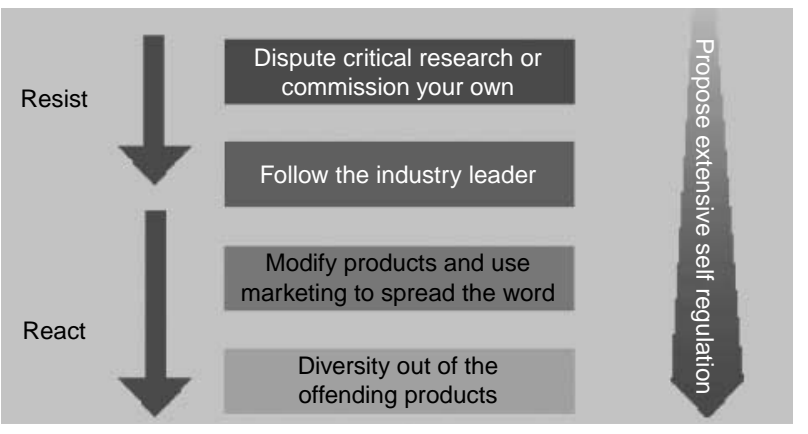

Fig. 1 How the advertising industry responds to change ${ }^{37}$

is of crucial importance and a possible barrier for the furtherance of public health nutrition and food policy.

Experiences from the global and UK levels show this resistance and reaction. The WHO/FAO's publication of its technical report Diet, Nutrition and the Prevention of Chronic Diseases prompted sections of the food industry to responded with challenges and strong lobbying of government and policy-makers; for example, the sugar lobby in the USA threatened to 'scupper WHO' by lobbying for an end to US Government funding ${ }^{38,39}$. Hirschhorn $^{39}$ also reported that undue influence was exerted on specific FAO/WHO food policies dealing with dietary guidelines, pesticides use, additives, trans fatty acids and sugar. This process is also reflected at a national level. Similar lobbying pressure was exerted in relation to the Hastings review in the UK. Sir John Krebs of the Food Standards Agency (FSA) has been reported as standing by the findings of the Hastings review and members of the FSA board have been reported as disappointed at the industry challenges of the review and the questioning of the 'mandate of the FSA' 40 . In addition, as an act of reaction the industry sponsored its own review ${ }^{32}$. In its 2002-2003 review ${ }^{41}$, the AA said of the Hastings review ${ }^{7}$ :

The Food Standards Agency has gone ahead with its review of research on the effects on bealth of the promotion of foods to children despite the fact that the research framework, as the Food Advertising Unit has repeatedly highlighted, would appear to pre-suppose the findings - expected in June.

The text then goes on to cast doubt on the integrity of some of the same research team when it says:

[T]he situation is not belped by the fact that some of the academics involved are on public record as being in favour of banning food advertising to children.

The 2004-2005 AA review ${ }^{42}$ saw the proposals in the UK public health White Paper ${ }^{43}$ as a threat and engaged in pointing out what they called the inconsistencies in the regulatory impact assessment that accompanies the White Paper. The 2004-2005 review does adopt a more conciliatory tone when the Director General said that "the opportunity to regain the initiative and be "part of the solution" now exists ${ }^{42}$, indicating that some advantage 
had been gained by those proposing limits on TV advertising aimed at children. The current examinations of the food industry and the role of advertising, as well as the shift to other forms of marketing, have alarmed the advertising industry ${ }^{5}$.

The food industry's approach to policy development is to stymie it by producing counter-arguments/research and pointing out the importance of the industry in financial terms, emphasising the impact that bans or regulation would have on the wealth creation aspect of the industry.

But it is not just public health campaigners who are expressing concern; within the industry itself are heard words of warning with reports on obesity and food companies by UBS Warburg ${ }^{44}$ and JP Morgan ${ }^{45}$ (a branch of JP Morgan Securities Inc.). The analysts at UBS Warburg point out that trade bodies expend a lot of energy pointing out discrepancies in evidence that WHO uses to support its conclusions', this being seen as an appropriate way to block and resist policy development. The UBS Warburg report summarises the industry position as that expected of an interest group who wants to maintain the status quo but also says "[T]hat the very force of the counter arguments convinces us that this is a very major issue facing the food and drinks industry'. Once change becomes inevitable the UBS Warburg analysts predict that the food industry will change from protecting the status quo to limiting and slowing down the changes. Both reports concluded that:

- The rise in obesity raises serious concerns and threats for the food industry.

- The food industry will have to review its marketing practices and adapt itself to address these concerns.

- Food manufacturers face the risk of increased regulation and litigation and will have to work with regulatory authorities to devise marketing guidelines, which will inevitably be more restrictive than current guides.

- The soft drinks and snacks sectors are in particular danger as they are identified by academic research as contributory factors to obesity.

- Global concerns with obesity create an opportunity for players focused on healthy segments of the industry and with food portfolios that are focused on the health side.

Proposals for outright bans are likely to run into huge opposition; the AA warned that any attempt to ban food advertising that could be harmful to children would be subject to appeal under Article 10 of the Human Rights Act as follows ${ }^{46}$ :

Commercial freedom of speech is recognised and enshrined in the Human Rights Act (Article 10). Whilst there are derogations allowed for the protection of public health, for example, the panel is unable to offer any evidence that brand advertising of particular products impacts on dietary choice and thus on health, nor does any evidence exist that such advertising has long-term bealth implications for children or adults. Thus any proposal to ban or further restrict advertising of particular categories of food would be a de facto infringement of commercial freedom of speech and would face immediate challenge.

A major policy weakness of the majority of countries in Europe lies in the use of voluntary codes, their operation through self-regulation and the appointment of members to these regulatory bodies. The policy 'advantage' is with the adverting industry in the absence of statutory controls and a public health voice on these panels. There is a need at national government and EU levels for an independent agency to lead on the development of standards on children and advertising.

\section{Conclusions}

At national level the mechanisms exist to place controls on food advertising, but the lessons from Sweden and Quebec show that such an approach has to be transnational to be effective. For this reason any national initiatives need to be truly supported by international agreements or controls which regulate the airwaves across national boundaries ${ }^{1}$. The policy options for advertising aimed at children are threefold:

- A complete ban on advertising, as in the case of Sweden.

- Partial restrictions on advertising by type of food, target group or limits on the amount of advertisements or times shown.

- Setting of upper or lower limits on advertisements by time/place or programming or containing warning messages.

Public health nutrition needs to articulate with a clear voice its position on food advertising targeted at children. A good model exists in Australia through the Coalition on Food Advertising to Children (http://www.chdf.org.au/icms_wrapper?page $=666 \&$ issurvey $=$ \&rand $=0.9432700755855862$ ), which gives a voice to nutritionists and parents. In addition the monitoring and impact of advertising inputs are required from the perspective of the impact on public health ${ }^{47}$. At the moment the most basic data on input are collected and not translated into nutrition impacts. Public health nutrition needs to ensure that these concerns are heard and reflected within whatever regulatory framework is adopted.

\section{Acknowledgements}

Conflict of interest: M.C. was one of the authors of the Hastings report ${ }^{7}$ and has been involved in consultations in Ireland and Sweden on children and TV advertising. J.L. was the UK national coordinator for the European Heart Network report ${ }^{2}$ on marketing unhealthy food to children. 


\section{References}

1 Hawkes C. Marketing Food to Children: The Global Regulatory Environment. Geneva: World Health Organization, 2004.

2 Matthews A, Cowburn G, Rayner M, Longfield J, Powell C. The Marketing of Unbealthy Food to Children in Europe. A Report of Phase 1 of the 'Children, Obesity and Associated Avoidable Chronic Diseases' project. Brussels: European Heart Network, 2005.

3 World Health Organization (WHO)/Food and Agriculture Organization. Diet, Nutrition and the Prevention of Chronic Diseases. Technical Report Series No. 916. Geneva: WHO, 2003.

4 Crister G. Fat Land. Boston, MA: Houghton Mifflin Company, 2003.

5 Lindstrom M. BRANDchild. London: Kogan Page, 2003.

6 Anon. Norway prepares crackdown on food advertising to children. EU Food Law, 11 March 2005; (203): 15.

7 Hastings G, Stead M, McDermott L, Forsyth A, MacKintosh A, Rayner M, et al. Review of the Research on the Effects of Food Promotion to Children. Glasgow: Centre for Social Marketing, 2003.

8 Ofcom (Office of Communications). Childhood Obesity Food Advertising in Context: Children's Food Choices, Parents' Understanding and Influence, and the Role of Food Promotion. London: Ofcom, 2004.

9 Fleck F. WHO challenges food industry in report in diet and health. British Medical Journal 2003; 326: 515.

10 Margetts B. FAO/WHO launch expert report on diet, nutrition and prevention of chronic diseases [Editorial]. Public Health Nutrition 2003; 6: 323-5.

11 Anon. French agency favours ban on TV adverts aimed at children. EU Food Law, 16 July 2004; (175): 1.

12 World Health Organization (WHO). Global Strategy on Diet, Physical Activity and Health. WHA57.17. Geneva: WHO, 2004.

13 Landon J. TVAdvertising and Children: Review of Regulatory Frameworks by Country. London: National Heart Forum, 2003.

14 Dibb S. Children: Advertisers'Dream, Nutrition Nightmare. London: National Food Alliance, 1993.

15 Lee K, Buse K, Fustukian S. Health Policy in a Globalising World. Cambridge: Cambridge University Press, 2002.

16 Lee K. Globalization and Health: An Introduction. London: Palgrave, 2003.

17 Jarlbro G. Children and Television Advertising. The Players, the Arguments and the Research during the Period 19942000. Stockholm: Swedish Consumer Agency, 2001.

18 European Commission, Directorate-General for Education and Culture. Television Without Frontiers Directive (89/552/EEC). Brussels: European Commission, 1997 (amended 97/36/EC, 1997).

19 European Commission. Fourth Report on the Integration of Health Protection Requirements in Community Policies. V/1999/408-EN. Brussels: European Commission, 1999.

20 Castle S. Brussels aims to outlaw misleading labels on food. The Independent, 17 July 2003; 8.

21 Anon. 'Healthy' food labels to go. The Telegraph, 17 July $2003 ; 2$.

22 Watts R. Eurotrashed [Sunday Telegraph Business Focus]. Sunday Telegraph, 12 September 2004; 6.

23 Ashton D. Food advertising and childhood obesity. Journal of the Royal Society of Medicine 2004; 97: 51-2.

24 González del Valle A. An Overview and Comparison of Rules, Regulations and Policies Affecting Advertising to Children in The Netherlands, UK, Spain and Sweden. London: The Children's Programme of the Food Advertising Unit, 1999.
25 NOP Solutions for the Children's Programme. Pester Power: A Report on Attitudes in Spain and Sweden. London: NOP, 1999.

26 Bjurström E. Children and Television Advertising, A Critical Study of International Research Concerning the Effects of TV Commercials on Children. Stockholm: Swedish Consumer Agency, 1994.

27 Swedish National Institute of Public Health (SNIPH). SIFO Advertising Evaluations. Stockholm: SNIPH, 2004.

28 National Food Administration/National Institute of Public Health. Background Material to The Action Plan for Healthy Dietary Habits and Increased Physical Activity. Uppsala/Stockholm: National Food Administration/National Institute of Public Health, 2005.

29 Quinn R-BM. Children's Advertising Code: Phase Two Consultation Document Review of Adult Submissions Received. Dublin: Broadcasting Commission of Ireland, 2004.

30 Humphreys J. Martin rules out tax on junk food. Irish Times, 11 March 2004; 11.

31 Department of Trade and Industry (DTI). A New Future for Communications. London: DTI, 2000. Also available at http://www.dti.gov.uk. Accessed 18 July 2004.

32 Department of Health (DoH). Choosing a Better Diet: A Food and Health Action Plan. London: DoH, 2005.

33 Incorporated Society of British Advertisers (ISBA). ISBA Briefing Paper Issue: Advertising and Children. London: ISBA, 2002.

34 Young B. Advertising and Food Choice in Children: A Review of the Literature. Exeter: School of Psychology, University of Exeter, 2003.

35 James WPT, Ralph A, Bellizzi M. Nutrition policies in Western Europe: national policies in Belgium, the Netherlands, France and the United Kingdom. Nutrition Reviews 1997; 55: S4-20.

36 Schlosser E. Fast Food Nation: The Dark Side of the AllAmerican Meal. Boston, MA: Houghton Mifflin Company, 2001.

37 Curry A, Kelnar R. Fat is a Strategic Issue. London: Henley Centre, 2004

38 Boseley S. Sugar industry threatens to scupper WHO. The Guardian, 21 April 2003; 1-2.

39 Hirschhorn MD. How the tobacco and food industries and their allies tried to exert undue influence over FAO/WHO food and nutrition policies. Unpublished report to the World Health Organization, 2002.

40 Anon. FSA agrees next steps on children and food promotion. heartforum Summer 2004; (18): 6.

41 The Advertising Association. Annual Review 2002-2003. London: The Advertising Association, 2003.

42 The Advertising Association. Annual Review 2004-2005. London: Advertising Association, 2005.

43 Department of Health. Choosing Health: Making Healthy Choices Easier. CM 6374. London: The Stationery Office, 2004.

44 UBS Warburg. Global Equity Research: Absolute Risk of Obesity. London: UBS Warburg, 2002.

45 JP Morgan. Food Manufacturing: Obesity the Big Issue. London: JP Morgan European Equity Research, 2003.

46 The Advertising Association. A Submission to the Food Chain and Crops for Industry Panel's Consultation Paper: 'Food's Contribution to Health in the Future' - The Foresight Programme. London: Advertising Association, 2000.

47 Coalition on Food Advertising to Children. A Briefing Paper by the Coalition on Food Advertising to Children (CFAC). Adelaide: Department of Nutrition and Dietetics, Flinders University, November 2003. 